\title{
Sedimentation process and mechanism of Cd in Jiaozhou Bay
}

\author{
Dongfang Yang ${ }^{1,2,3}$, Zhikang Wang ${ }^{1,2}$, Chunhua Su ${ }^{1,2}$, Sixi Zhu ${ }^{1,2}$, Fengyou \\ Wang ${ }^{1,2}$ \\ ${ }^{1}$ Research Center for Karst Wetland Ecology, Guizhou Minzu University, Guiyang 550025, China; \\ ${ }^{2}$ College of Chemistry and Environmental Science, Guizhou Minzu University, Guiyang 550025, \\ China; \\ ${ }^{3}$ North China Sea Environmental Monitoring Center, SOA, Qingdao 266033, China.
}

Keywords: Cd; Content, Distribution, Sedimentation process, Jiaozhou Bay.

\begin{abstract}
This paper analyzed the content, pollution level and distribution Cd in Jiaozhou Bay based on the investigation data in May, August and November 1979. Results showed that the contents of Cd were 0.01-0.09 $\mu \mathrm{g} \mathrm{L}^{-1}$, and were confirm to Grade I in according to National Standard of China for Seawater Quality (GB3097-1997), indicated that this bay had not been polluted by Cd in 1979. It was found that there was a high sedimentation region in the inner side of the bay mouth in May and August, while in November there was a high sedimentation region in the outer side of the bay mouth. Furthermore, we revealed the sedimentation process and mechanism of $\mathrm{Cd}$ and identified the change process in bottom waters. In generally, the sedimentation of Cd was mainly determined by the source strength of $\mathrm{Cd}$ and the distance from the source.
\end{abstract}

\section{Introduction}

Cd is one of the widely used heavy metal elements in industries. A large amount of Cd-containing wastes were generated and discharged to the environment along with the rapid development of industry and population. Hence, many marine bays were polluted by $\mathrm{Cd}$ since ocean is the sink of various pollutants [1-10]. Therefore, understanding of the transfer process of Cd in marine bay is essential to environmental protection.

Jiaozhou Bay is a semi-closed bay located in Shandong Province, eastern China. This bay had been polluted by various pollutants including $\mathrm{Pb}$ after China's reform and opening-up [1-6]. Based on investigation data in May, August and November 1979, the aim of this paper was to analyze the content, pollution level and distribution of $\mathrm{Cd}$, to reveal the sedimentation process and mechanism, and to provide scientific basis for pollution control.

\section{Material and method}

Jiaozhou Bay is located in the south of Shandong Province, eastern China $\left(35^{\circ} 55^{\prime}-36^{\circ} 18^{\prime} \mathrm{N}\right.$, $120^{\circ} 04^{\prime}-120^{\circ} 23^{\prime} \mathrm{E}$ ), with the total area and average water depth of $446 \mathrm{~km}^{2}$ and $7 \mathrm{~m}$, respectively. This bay is a typical of semi-closed bay connected to the Yellow Sea in the south, with a bay mouth with of $3 \mathrm{~km}$. There are a dozen of rivers including Dagu River, Haibo Rriver, Licun Rriver, and Loushan Rriver etc., all of which are seasonal rivers [11-12]. The investigation on Cd in bottom waters in Jiaozhou Bay was carried on in May, August and November 1979 in three investigation sites (i.e., H34, H35, H36) (Fig. 1). Pb in waters was sampled and monitored follow by National Specification for Marine Monitoring [13]. 


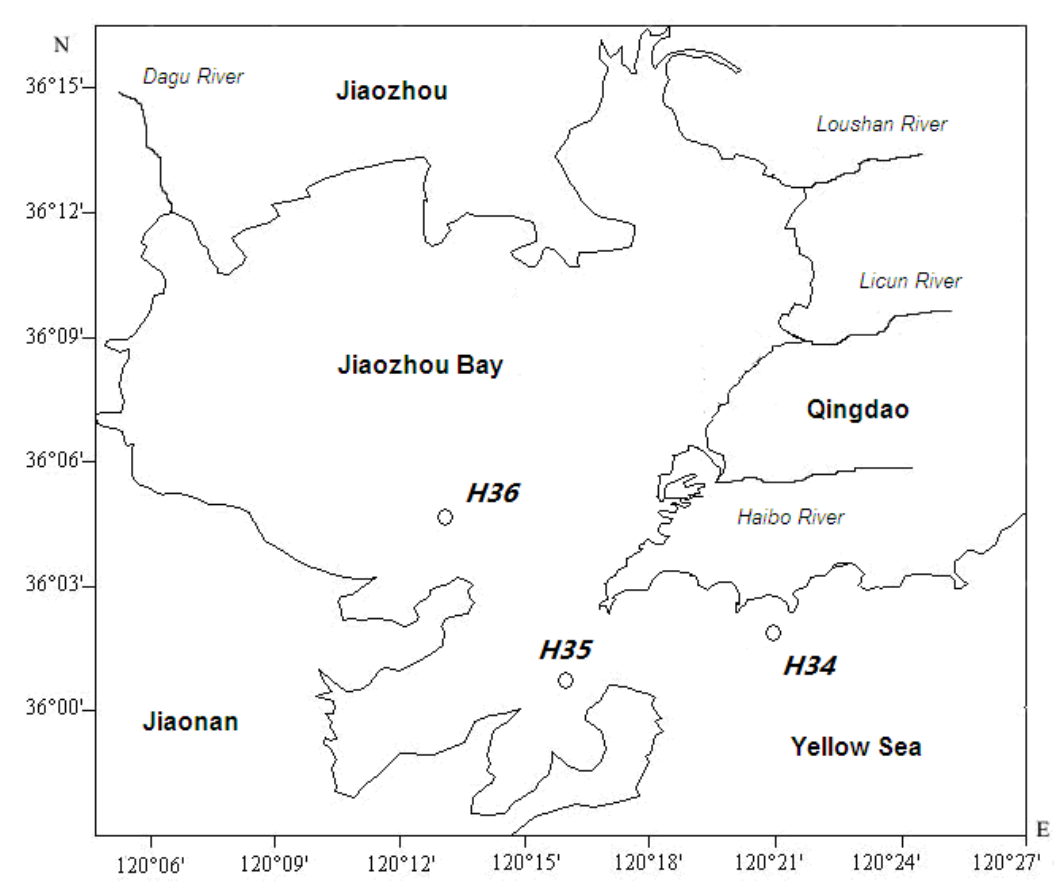

Fig. 1 Geographic location and sampling sites in Jiaozhou Bay

\section{Results and discussion}

\subsection{Content and pollution level of $\mathrm{Cd}$.}

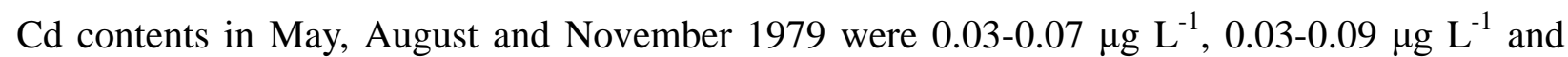
0.01-0.02 $\mu \mathrm{g} \mathrm{L}^{-1}$, respectively, all of which were lower than guideline of Grade I for Cd $\left(1.00 \mu \mathrm{g} \mathrm{L}^{-1}\right)$ in National Standard of China for Seawater Quality (GB3097-1997), indicated that this bay had not been polluted by $\mathrm{Cd}$ in the beginning of China's Reform and Opening-up. River runoff was the major Cd source in May and August, while marine current was responsible in November. However, by means of vertical water's effect [14], Cd contents in bottom waters were decreasing to a very low level.

\subsection{Distribution and sedimentation process of $\mathrm{Cd}$.}

The sampling sites of H36, H35 and H34 were located in the inner side of the bay mouth, the middle of the bay mouth and the outer side of the bay moth, respectively (Fig. 1). In May and August 1979, Cd contents were decreasing from the inner side of the bay mouth to the outer side of the bay mouth (Fig. 2a,b ). However, Cd contents were decreasing from the outer side of the bay mouth to the inner side of the bay moth in November (Fig. 2c). By means of the water exchange from open waters, the contents of the substances in the bay were decreasing continuously. Meanwhile, the contents of the substances in the open waters could also be decreasing continuously bay means of the water exchange from the bay [15]. In according to the spatial distribution of Cd in bottom waters in May and August, it was found that there were high and low sedimentation regions inside and outside the bay mouth, respectively. However, there were low and high sedimentation regions inside and outside the bay mouth in November, respectively. 

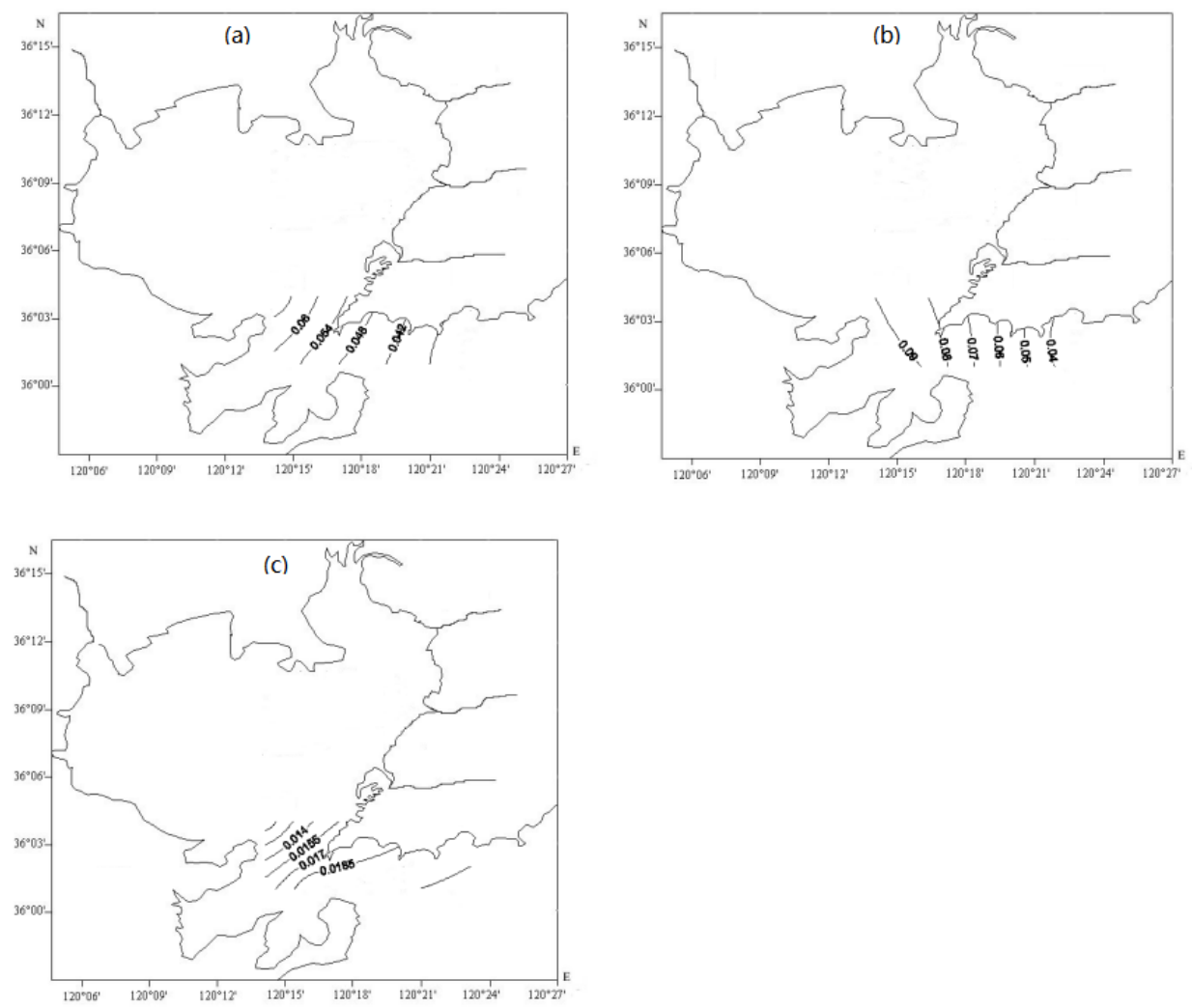

Fig. 2 Horizontal distributions of Cd in bottom water in Jiaozhou Bay in a) May, b) August and c) November $1979 / \mu \mathrm{g} \mathrm{L}{ }^{-1}$

\subsection{Sedimentation mechanism of Cd.}

Once Cd was transported from the sources to the bay, it was firstly transported to surface waters, and was finally transported to bottom waters. River runoff was the major Cd source in May and August, and Cd contents were settling from the inner side of the bay mouth to the outer side of the bay mouth along with the flow direction of the rivers continuously. Marine current was the major Cd source in November, and Cd contents were settling from the outer side of the bay mouth to the inner side of the bay mouth along with the flow direction of the marine current continuously. In generally, the closer of the distance to the source the higher sedimentation rate, and the farther of the distance to the source the lower sedimentation rate. That was the sedimentation mechanism of $\mathrm{Cd}$ in marine bays. Hence, there were high and low sedimentation regions inside and outside the bay mouth in May and August, respectively, yet were low and high sedimentation regions inside and outside the bay mouth in November, respectively.

\section{Conclusions}

Cd contents in May, August and November 1979 were $0.03-0.07 \mu \mathrm{g} \mathrm{L} \mathrm{L}^{-1}, 0.03-0.09 \mu \mathrm{g} \mathrm{L}{ }^{-1}$ and 0.01-0.02 $\mu \mathrm{g} \mathrm{L}^{-1}$, respectively, indicated that this bay had not been polluted by $\mathrm{Cd}$. There were high and low sedimentation regions inside and outside the bay mouth in May and August, respectively, yet were low and high sedimentation regions inside and outside the bay mouth in November, respectively. The sedimentation mechanism of Cd was that, the closer of the distance to the source the higher sedimentation rate, and the farther of the distance to the source the lower sedimentation rate. In generally, the sedimentation of Cd was mainly determined by the source strength of Cd and the distance from the source.

\section{Acknowledgments}

This research was sponsored by the China National Natural Science Foundation (31560107), 
Doctoral Degree Construction Library of Guizhou Nationalities University, Education Ministry's New Century Excellent Talents Supporting Plan (NCET-12-0659) and Research Projects of Guizhou Nationalities University ([2014]02), Research Projects of Guizhou Province Ministry of Education (KY [2014] 266), Research Projects of Guizhou Province Ministry of Science and Technology (LH [2014] 7376).

\section{References}

[1] Yang DF, Chen Y, Wang H, et al.: Coastal Engineering, Vol. 29 (2010), p. 73-82. (in Chinese)

[2] Yang DF, Chen Y, Liu CX, et al.: Coastal Engineering, Vol. 32(2013), p. 68-78. (in Chinese)

[3] Yang DF, Zhu SX, Wang FY, et al.: Applied Mechanics and Materials, Vol.644-650( 2014), p. 5325-5328.

[4] Yang DF Wang FY, Wu WF, et al.: Applied Mechanics and Materials, Vol. 644-650( 2014), p.5329-5312.

[5] Yang DF, Chen ST, Li BL, et al.: Proceedings of the 2015 international symposium on computers and informatics, Vol. (2015), p. 2667-2674.

[6] Yang DF, Zhu SX, Yang XQ, et al:Materials Engineering and Information Technology Application, Vol. (2015), p. 558-561.

[7] Yang DF, Zhu SX, Wang FY, et al.:Advances in Computer Science Research, Vol. (2015), p.194-197.

[8] Yang DF, Wang FY, Sun ZH, et al: Advances in Engineering Research, Vol. 40(2015), p.776-781.

[9] Yang DF, Yang DF, Zhu SX, et al.:Advances in Engineering Research. Vol. (2016), Part B, p. 403-407.

[10] Yang DF, Wang XQ, Wang M, et al.:Advances in Engineering Research, Vol. (2016), Part B, p. 412-415.

[11] Yang DF, Chen Y, Gao ZH, et al.: Chinese Journal of OceanoLogy and LimnoLogy, Vol. 23(2005), p. 72-90. (in Chinese)

[12] Yang DF, Wang FY, Gao ZH, et al. Marine Science, Vol. 28 (2004), p. 71-74. (in Chinese)

[13] China's State Oceanic Administration: The specification for marine monitoring (Ocean Press, Beijiang 1991), p.205-282. (in Chinese)

[14] Yang DF, Wang FY, He HZ, et al.:Proceedings of the 2015 international symposium on computers and informatics, Vol. (2015), p. 2655-2660.

[15] Yang DF, Miao ZQ, Xu HZ et al.: Marine Environmental Science, Vol. 32 (2013), p. 373-380. 